\title{
Produção e qualidade fisiológica de sementes de soja em diferentes ambientes de cultivo
}

\section{Seed yield and physiological quality of soybean in different environments}

\author{
Greice Daiane Rodrigues Gomes ${ }^{1}$; Giovani Benin ${ }^{1 *}$; \\ Rui Colvara Rosinha²; Danielle Galvan ${ }^{1}$; Eduardo Stefani Pagliosa ${ }^{1}$; \\ Cilas Pinnow ${ }^{1}$; Cristiano Lemes da Silva ${ }^{1}$; Eduardo Beche ${ }^{1}$
}

\section{Resumo}

O objetivo deste estudo foi avaliar a qualidade fisiológica e o rendimento de sementes de diferentes cultivares de soja produzida nos municípios de Campo Mourão e Guarapuava, Estado do Paraná e, Guaíra no Estado de São Paulo. Sementes de nove cultivares, provenientes da rede de ensaios da Fundação Pró-Sementes, foram utilizadas para as análises. O delineamento experimental foi em blocos ao acaso, em esquema fatorial 9 x 3 (cultivares x ambientes), com 3 repetições. A avaliação da qualidade da semente foi realizada pelo teste de germinação e vigor, e pelos testes de Envelhecimento Precoce e Tetrazólio. Verificou-se que a qualidade fisiológica e o rendimento das sementes foi influenciada pelo ambiente de cultivo. Sementes de soja provenientes da região de Guarapuava-PR apresentam maior germinação, vigor e viabilidade, em comparação as regiões de Campo Mourão-PR e Guaíra-SP. Os danos mecânicos e de umidade foram os principais causas pela diminuição da germinação, vigor e viabilidade das sementes em todos os locais avaliados. As cultivares CD 214 RR, BRS 246 RR e BRS $255 \mathrm{RR}$ apresentaram elevado rendimento e qualidade fisiológica de sementes.

Palavras-chave: Glycine max, germinação, vigor, interação genótipo x ambiente

\begin{abstract}
The objective of this study was to evaluate the physiological quality and seed yield of soybean cultivars produced in Campo Mourão and Guarapuava, Paraná State, and Guaíra in the São Paulo State. Seeds of nine cultivars from trials network of the Fundação Pró-Sementes were used for analysis. The experimental design was in randomized blocks in factorial scheme 3 x 9 (cultivars x environments), with three replications. The evaluation of seed quality was performed using the germination and vigor tests, and through the accelerated aging and Tetrazolium tests. The results showed that the physiological quality and seed yield were influenced by the sowing environment. Soybeans seeds from the region of Guarapuava-PR had higher germination, vigour and viability, compared the regions of Campo Mourão-PR and Guaíra-SP. The mechanical and moisture damage were mainly causes for the decrease in germination, vigor and viability of seeds at all regions evaluated. The cultivars CD 214 RR, BRS 246 and BRS 255 RR showed high yield and seed quality.
\end{abstract}

Key words: Glycine max, seed germination, vigor, genotype x environment interaction

\footnotetext{
${ }^{1}$ Universidade Tecnológica Federal do Paraná, Campus Pato Branco, Rodovia do Conhecimento, Km 1, CEP 85503-390, Pato Branco, PR. E-mail: greicee@hotmail.com.br; benin@utfpr.edu.br; galvande@gmail.com; eduardopagliosa@yahoo.com.br; cilaspinnow@gmail.com; cristianolemes.utfpr@gmail.com; eduardo_beche@hotmail.com

${ }^{2}$ Pesquisador da Fundação Pró-Sementes de Apoio a Pesquisa, Rua Diogo de Oliveira 640, CEP 99025-130, Passo Fundo, RS. E-mail: rcrosinha@gmail.com

* Autor para correspondência
} 


\section{Introdução}

$\mathrm{Na}$ produção de soja, um dos aspectos mais importante é o uso de sementes de elevada qualidade, que garantem uma emergência adequada e homogênea de plântulas em nível de lavoura (FRANÇA NETO; KRZYZANOWSKI, 1990; BRACCINI et al., 1999). A qualidade das sementes reflete diretamente no desenvolvimento da cultura, gerando plantas de elevado vigor, uniformidade de população, ausência de doenças transmitidas via semente (SILVA; LAZARINI; SÁ, 2010) e maior capacidade competitiva (KOLCHINSKI, 2003), fatores esses que podem influenciar diretamente o rendimento de grãos (KOLCHINSKI; SCHUCH; PESKE, 2005; SCHEEREN et al., 2010). Já sementes de baixa qualidade demostram sintomas típicos de envelhecimento, tais como baixa viabilidade, redução da germinação e taxa de emergência, baixa tolerância a condições sub-ótimas e reduzida taxa de crescimento de plântulas (HAMAWAKI et al., 2002).

As sementes de soja são extremamente sensíveis a fatores ambientais. A região de cultivo pode determinar a qualidade fisiológica da semente a ser produzida, na medida em que proporciona melhores ou piores condições de umidade e temperatura durante a maturação das plantas (COSTA et al., 2003; 2005). Além disso, essas variações ambientais proporcionam interações diferenciadas entre cultivares e ambientes de cultivo (LIMA et al., 2008; MARQUES et al., 2011; MEOTTI et al., 2012).

De acordo com Costa et al. (2003), que estudaram a qualidade de sementes de soja no Brasil, as sementes provenientes do sul do Paraná e do Estado do Rio Grande do Sul apresentam um melhor padrão de qualidade fisiológica em função de baixos índices de deterioração por umidade e lesões de percevejos. Vasconcelos et al. (2009) avaliando a qualidade de sementes de soja em diferentes locais de Minas Gerais, encontraram grande influência do ambiente na qualidade fisiológica das sementes.
Sendo assim, dada a ampla diversidade climática nas regiões de cultivo de soja no Brasil, aliada ao lançamento anual de grande número de cultivares com diferentes graus de sensibilidade aos fatores ambientais, faz-se necessário avaliar o potencial fisiológico de sementes de soja produzidas em locais com diferentes condições edafoclimáticas. Desta forma, o objetivo deste trabalho foi avaliar a qualidade fisiológica e física de sementes de nove cultivares de soja, produzidas em distintas regiões dos estados do Paraná e São Paulo.

\section{Material e Métodos}

O experimento foi realizado com sementes provenientes de ensaios conduzidos pela Fundação Pró-Sementes de Apoio à Pesquisa, em parceria com a Embrapa Trigo, na safra 2006/2007, nos municípios de Guarapuava e Campo Mourão no Paraná e Guaíra no estado de São Paulo.

O clima de Campo Mourão é classificado como Cfa (Clima Subtropical Úmido mesotérmico), com verões quentes e geadas pouco freqüentes, com tendência de concentração das chuvas nos meses de verão, sem estação seca definida. A média das temperaturas dos meses mais quentes é superior a $22^{\circ} \mathrm{C}$ e a dos meses mais frios é inferior a $18^{\circ} \mathrm{C}$. A temperatura média anual está entre $20^{\circ} \mathrm{C}$ e $21^{\circ} \mathrm{C}$, possui altitude de $630 \mathrm{~m}$ e está localizado na latitude $24^{\circ} 02^{\prime}$. O clima de Guarapuava é classificado como $\mathrm{Cfb}$ (Clima Subtropical Úmido Mesotérmico), com verões frescos, temperatura média inferior a $22^{\circ} \mathrm{C}$, invernos com ocorrências de geadas severas e frequentes, temperatura média superior a $3^{\circ} \mathrm{C}$ e inferior a $18^{\circ} \mathrm{C}$, não apresentando estação seca, possui altitude de $1058 \mathrm{~m}$ e está localizado na latitude $25^{\circ} 21^{\prime}$. O clima de Guaíra é classificado como Cwa (Clima Temperado Húmido), caracterizando-se por clima quente, inverno seco, temperatura média acima de $22^{\circ} \mathrm{C}$ no mês mais quente e abaixo de $18^{\circ} \mathrm{C}$ no mês mais frio, possui altitude de $517 \mathrm{~m}$ e está localizado na latitude $20^{\circ} 19^{\prime}$. Os dados climáticos referentes ao período de realização do experimento são apresentados na figura 1 . 
Sementes das cultivares de soja CD 212 RR, CD 213 RR, CD 214 RR, de ciclo precoce, BRS 242 RR, BRS 244 RR e BRS 255 RR de ciclo semi-precoce e BRS 243 RR, BRS 246 RR e BRS 247 RR de ciclo médio, foram utilizadas no experimento (Tabela 1). O delineamento experimental foi em blocos ao acaso, em esquema fatorial 9 × 3 (cultivares $\mathrm{x}$ ambientes), com 3 repetições. As parcelas foram constituídas de 4 linhas de $5 \mathrm{~m}$ de comprimento, com espaçamento de $0,5 \mathrm{~m}$, totalizando uma área útil de 4 metros quadrados. A adubação o controle de pragas e de plantas daninhas foi realizado de acordo com as recomendações técnicas indicadas para a cultura da soja (EMBRAPA, 2006). A partir da área útil das parcelas foi estimado o rendimento de sementes em $\mathrm{kg} \mathrm{ha}^{-1}$, corrigido para $13 \%$ de umidade.

Os testes de qualidade de sementes utilizados foram o de germinação, envelhecimento precoce e o de tetrazólio (vigor e viabilidade), foram implementados conforme prescritos pelas metodologias oficiais (ABRATES, 1999; BRASIL, 2009).

Germinação: utilizaram-se oito repetições de 50 sementes cada, distribuídas em papel toalha, "Germitest", o qual a umidade foi ajustada na proporção de 2,5 vezes o peso do substrato seco. Em seguida as amostras foram acondicionadas em germinador durante sete dias utilizando-se a temperatura constante de $25^{\circ} \mathrm{C}$. Sendo que no quinto dia foi realizada a leitura das amostras para determinação do vigor e no sétimo dia para determinação do percentual germinação.

Envelhecimento Precoce: Foram utilizadas 400 sementes divididas em duas subamostras de 200 sementes, distribuídas em camada única sobre a tela. No fundo das caixas plásticas, do tipo gerbox (11,0 x 11,0 x 3,0cm) foram colocados $40 \mathrm{~mL}$ de água destilada. As caixas com sementes de soja foram mantidas em câmara de germinação do tipo DBO com temperatura constante de $41^{\circ} \mathrm{C}$ por período de
48 horas. Após este período de envelhecimento, as sementes foram colocadas para germinar, conforme teste de germinação descrito acima.

Tetrazólio (vigor e viabilidade): foram utilizadas duas subamostras de 50 sementes cada, as mesmas passaram por um pré-condicionamento em papel toalha "Germitest", umedecido por 16 horas, sendo posteriormente colocadas numa solução $0,075 \%$ de sal de tetrazólio, por três horas, em DBO a $35^{\circ} \mathrm{C}$. Após este processo as sementes foram avaliadas individualmente. Realizando seccionamento longitudinal das sementes entre os cotilédones (com o cuidado para que o eixo embrionário fosse dividido ao meio nessa secção longitudinal), com o auxílio de uma lâmina de barbear. Após o corte das sementes, as duas metades foram separadas e o tegumento removido para a exposição da superfície externa dos cotilédones, observando-se a ocorrência dos danos mecânicos, por percevejos e deterioração por umidade, nas partes externas e internas dos cotilédones; dando-se atenção especial ao eixo embrionário. Durante a leitura e a interpretação foi observado, com detalhes, se a ocorrência de determinado dano no eixo embrionário era superficial, atingindo apenas o córtex ou se afetava o cilindro central. Para a informação dos resultados do referido teste, cada semente foi analisada e classificada em classes de viabilidade de 1 a 8 . Após essa avaliação, registraram-se os níveis de vigor, de viabilidade e a identificação da(s) causa(s) que possa(m) ter determinado a citada classe. A somatória dos percentuais das classes 1 a 3 resultou no índice de vigor (TZ 1-3) e a somatória de 1 a 5 no índice de viabilidade (TZ 1-5) das sementes de cada cultivar. Por sua vez, o diagnóstico de perda de qualidade foi efetuado através do exame das sementes incluídas nas classes 6 a 8, identificandose as causas determinantes (dano mecânico, lesões de percevejos e deterioração por umidade), cujos resultados foram expressos em percentagem, segundo França Neto, Krzyzanowski e Costa (1998). 
Tabela 1. Características agronômicas das nove cultivares avaliadas nos ensaios dos municípios de Guarapuava-PR, Campo Mourão - PR e Guaíra na safra 2006/2007.

\begin{tabular}{lcccccc}
\hline Genótipo & Região de VCU* & $\begin{array}{c}\text { Estatura de Planta } \\
(\mathrm{cm})\end{array}$ & $\begin{array}{c}\text { Hábito de } \\
\text { Crescimento }\end{array}$ & $\begin{array}{c}\text { Maturação } \\
(\text { dias })\end{array}$ & Ciclo & $\begin{array}{c}\text { Peso de } 1000 \\
\text { grãos }(\mathrm{g})\end{array}$ \\
\hline CD 212 RR & RS-SC-PR** & $63-87$ & Determinado & $114-131$ & Precoce & 143 \\
CD 213 RR & RS-SC-PR-SP-MS & $73-84$ & Determinado & $104-132$ & Precoce & 159 \\
CD 214 RR & RS-SC-PR-SP-MS & $81-95$ & Determinado & $106-131$ & Precoce & 157 \\
BRS 242 RR & SC-PR-SP & 81 & Determinado & 122 & Semi-Precoce & 147 \\
BRS 244 RR & RS-SC-PR-SP & 76 & Determinado & 125 & Semi-Precoce & 150 \\
BRS 255 RR & SC-PR-SP & 78 & Determinado & 122 & Semi-Precoce & 160 \\
BRS 243 RR & RS-SC-PR-SP & 75 & Determinado & 123 & Médio & 126 \\
BRS 246 RR & RS-SC-PR-SP & 79 & Determinado & 126 & Médio & 139 \\
BRS 247 RR & SC-PR-SP & 73 & Determinado & 127 & Médio & 128 \\
\hline
\end{tabular}

*VCU - Valor de Cultivo e Uso. ** MS: Mato Grosso do Sul; PR: Paraná; SC: Santa Catarina; SP: São Paulo.

Fonte: COODETEC e EMBRAPA SOJA.

Os dados de rendimento de sementes e testes de qualidade de sementes foram submetidos a análise da variância e em seguida as médias foram comparadas pelo teste de Tukey, a 5\% de probabilidade de erro. As análises estatísticas foram realizadas através do software Genes (CRUZ, 2001).

\section{Resultados e Discussões}

Houve diferenças significativas $(p<0,01)$ para os fatores principais de cultivares e ambientes e para a interação cultivar $\mathrm{x}$ ambiente em todas as variáveis analisadas, indicando que as cultivares apresentaram desempenho diferenciado diante das variações ambientais (Tabela 2), conforme também verificado por Ávila et al. (2003) e Lima et al. (2008). Os coeficientes de variação apresentam de baixa magnitude $(5,3 \%$ a $10 \%)$, indicando boa confiabilidade das inferências testadas e elevada precisão experimental.

Tabela 2. Resumo da análise de variância incluindo as fontes de variação, seus respectivos quadrados médios e significâncias, e coeficientes de variação (C.V.\%) dos caracteres de qualidade fisiológica da semente; germinação (Germ), envelhecimento precoce (Env. Prec), vigor (Tz. Vig) e viabilidade (Tz. Viab) pelo teste de tetrazólio e o rendimento de sementes (RS) de nove cultivares de soja provenientes de ensaios realizados nos municípios de Guarapuava-PR, Campo Mourão-PR e Guaíra-SP, na safra 2006/2007.

\begin{tabular}{lcccccc}
\hline \multicolumn{1}{c}{ Fontes de Variação } & G.L. & Germ. & Env. Prec. & Tz. Vig & Tz. Viab. & RS \\
\hline Blocos & 6 & 17,1 & 8,3 & 70,8 & 10,4 & 43531,6 \\
Blocos/Ambientes & 2 & 11,7 & 2,6 & 7,9 & 13,6 & 365448,8 \\
Cultivares & 8 & $283,3^{* *}$ & $68,1^{* *}$ & $292,9^{* *}$ & $227,8^{* *}$ & $1166862,4^{* *}$ \\
Ambientes & 2 & $8918,9^{* *}$ & $45364,9^{* *}$ & $24921,9^{* *}$ & $10424,4^{* *}$ & $20207014,8^{* *}$ \\
Cultivares $x$ Ambientes & 16 & $242,7^{* *}$ & $133,3^{* *}$ & $249,3^{* *}$ & $239,1^{* *}$ & $305277,9^{* *}$ \\
Erro & 48 & 17,1 & 14,3 & 27,0 & 17,1 & 55528,8 \\
Média Geral & & $7 \ldots, \ldots \ldots \ldots \ldots \ldots \ldots \ldots$ \\
C.V. (\%) & & 78,6 & 53,3 & 51,8 & 74,0 & 3780,8 \\
\hline
\end{tabular}

valores significativos a $1 \%$ de probabilidade de erro pelo teste $\mathrm{F}$. GL total $=80$.

Fonte: Elaboração dos autores. 
Em Guarapuava-PR, o cultivar CD 212 RR apresentou rendimento de sementes superior, diferindo estatisticamente apenas das cultivares BRS 244 RR e BRS 242 RR (Tabela 3). Em Campo Mourão, o maior rendimento de sementes foi observado para a cultivar BRS 246 RR (4915 $\mathrm{kg} \mathrm{ha} \mathrm{h}^{-1}$, diferindo apenas das cultivares CD 212 RR e BRS 247 RR. Entretanto, para Guaíra-SP, o maior rendimento de sementes foi observado para a cultivar BRS $255 \mathrm{RR}$ (5277 $\left.\mathrm{kg} \mathrm{ha}^{-1}\right)$, não diferindo das cultivares BRS 246 RR e CD 214 RR. $\mathrm{O}$ município de Guarapuava-PR apresentou menor rendimento médio (2782 $\left.\mathrm{Kg} \mathrm{ha}^{-1}\right)$ quando comparado a Campo Mourão (4263 kg ha-1) e Guaíra (4297 kg $h^{-1}$ ) (Tabela 3). Não houve diferença estatística de comportamento das cultivares entre Campo Mourão e Guaíra, exceto para a cultivar BRS 255 RR.

Tabela 3. Rendimento de sementes $\left(\mathrm{kg} \mathrm{ha}^{-1}\right)$, de cultivares de soja provenientes de ensaios realizados nos municípios de Guarapuava-PR, Campo Mourão-PR e Guaíra-SP, na safra 2006/2007.

\begin{tabular}{lccc}
\hline \multirow{2}{*}{ Cultivares } & \multicolumn{3}{c}{ Rendimento de sementes $\left(\mathrm{kg} \mathrm{ha}^{-1}\right)$} \\
\cline { 2 - 4 } CD 212 RR & Guarapuava & Campo Mourão & Guaíra \\
CD 213 RR & $3137 \mathrm{abB}^{*}$ & $4758 \mathrm{bA}$ & $3902 \mathrm{bA}$ \\
CD 214 RR & $2801 \mathrm{abcB}$ & $4318 \mathrm{abA}$ & $4004 \mathrm{bA}$ \\
BRS 242 RR & $3009 \mathrm{abcB}$ & $410 \mathrm{abA}$ & $4882 \mathrm{abA}$ \\
BRS 243 RR & $2274 \mathrm{bcB}$ & $448 \mathrm{abA}$ & $4179 \mathrm{bA}$ \\
BRS 244 RR & $2668 \mathrm{abcB}$ & $4161 \mathrm{abA}$ & $3989 \mathrm{bA}$ \\
BRS 246 RR & $2057 \mathrm{cB}$ & $4915 \mathrm{aA}$ & $3962 \mathrm{bA}$ \\
BRS 247 RR & $2891 \mathrm{abcB}$ & $3725 \mathrm{bA}$ & $4533 \mathrm{abA}$ \\
BRS 255 RR & $2603 \mathrm{abcB}$ & $4460 \mathrm{abB}$ & $3940 \mathrm{bA}$ \\
Média Geral & $3595 \mathrm{aC}$ & $4263 \mathrm{~A}$ & $5277 \mathrm{aA}$ \\
C.V. (\%) & $2782 \mathrm{~B}$ & 4.42 & $4297 \mathrm{~A}$ \\
\multicolumn{1}{c}{ DMS Locais $=$} & 5.24 & DMS Cultivares & 7.71 \\
\hline
\end{tabular}

*Médias seguidas de mesma letra, minúsculas na coluna e maiúsculas na linha, não diferem estatisticamente entre si pelo teste de Tukey ao nível de 5\% de probabilidade de erro.

Fonte: Elaboração dos autores.

Os três locais de avaliação diferiram estatisticamente entre si quanto a germinação das sementes (Tabela 4). Desta forma, a maior média geral de germinação foi observada em Guarapuava (91\%), seguido de Campo Mourão (87\%) e Guaíra (58\%). Esses resultados concordam com os obtidos por Costa et al. (2003), os quais concluíram que sementes de soja provenientes do sul do Paraná e Rio Grande do Sul demonstraram qualidade fisiológica superior, quando comparadas com as demais regiões produtoras do Brasil. Esse resultados podem ser explicados pela variação pluvial e de temperatura (Figura 1), nos municípios de Campo Mourão e Guaíra, onde ocorreram temperaturas médias elevadas (acima de $24^{\circ} \mathrm{C}$ ) e altos índices pluviométricos; no município de Guarapuava, a temperatura média durante o desenvolvimento da cultura não excedeu os $23^{\circ} \mathrm{C}$. Temperaturas mais amenas favoreceram a qualidade da semente. Ao contrário, excesso de precipitação e temperatura elevada na maturação fisiológica/colheita, pode afetar de forma irreversível a qualidade da semente de soja (COSTA et al., 1994). 
Tabela 4. Valores em percentagem dos testes de germinação, envelhecimento precoce, tetrazólio (vigor e viabilidade) de nove cultivares de soja cultivados em Guarapuava-PR e Campo Mourão - PR e Guaíra-SP na safra 2006/2007.

\begin{tabular}{|c|c|c|c|c|c|c|}
\hline \multirow{2}{*}{ Cultivares } & \multicolumn{3}{|c|}{ Germinação } & \multicolumn{3}{|c|}{ Envelhecimento precoce } \\
\hline & Guarapuava & Campo Mourão & Guaíra & Guarapuava & Campo Mourão & Guaíra \\
\hline CD 212 RR & $94 \mathrm{aA}^{*}$ & $76 \mathrm{bB}$ & $29 \mathrm{dC}$ & $85 \mathrm{aA}$ & $58 \mathrm{cB}$ & $1 \mathrm{cC}$ \\
\hline CD 213 RR & $93 \mathrm{aA}$ & $89 \mathrm{abA}$ & $58 \mathrm{bcB}$ & $84 \mathrm{aA}$ & $78 \mathrm{abA}$ & $6 \mathrm{bB}$ \\
\hline CD 214 RR & $93 \mathrm{aA}$ & $91 \mathrm{abA}$ & $64 \mathrm{abB}$ & $80 \mathrm{aA}$ & $77 \mathrm{abA}$ & $3 \mathrm{bB}$ \\
\hline BRS 242 RR & $94 \mathrm{aA}$ & $91 \mathrm{abA}$ & $72 \mathrm{abB}$ & $66 \mathrm{bB}$ & $79 \mathrm{abA}$ & $12 \mathrm{aC}$ \\
\hline BRS 243 RR & $76 \mathrm{bB}$ & $94 \mathrm{aA}$ & $59 \mathrm{abcC}$ & $81 \mathrm{aA}$ & $85 \mathrm{aA}$ & $5 \mathrm{bB}$ \\
\hline BRS 244 RR & $88 \mathrm{abA}$ & $86 \mathrm{abA}$ & $75 \mathrm{aA}$ & $78 \mathrm{abA}$ & $75 \mathrm{abA}$ & $3 \mathrm{bB}$ \\
\hline BRS 246 RR & $96 \mathrm{aA}$ & $83 \mathrm{abB}$ & $46 \mathrm{cC}$ & $82 \mathrm{aA}$ & $67 \mathrm{bcB}$ & $4 \mathrm{bC}$ \\
\hline BRS 247 RR & $94 \mathrm{aA}$ & $85 \mathrm{abB}$ & $56 \mathrm{bcC}$ & $82 \mathrm{aA}$ & $73 \mathrm{abA}$ & $11 \mathrm{aB}$ \\
\hline BRS 255 RR & $92 \mathrm{abA}$ & $88 \mathrm{abA}$ & $61 \mathrm{abcB}$ & $75 \mathrm{abA}$ & $80 \mathrm{abA}$ & $8 \mathrm{abB}$ \\
\hline \multirow{2}{*}{ Cultivares } & \multicolumn{3}{|c|}{ Tetrazólio - Vigor } & \multicolumn{3}{|c|}{ Tetrazólio - Viabilidade } \\
\hline & Guarapuava & Campo Mourão & Guaíra & Guarapuava & Campo Mourão & Guaíra \\
\hline CD 212 RR & $81 \mathrm{abA}$ & $61 \mathrm{bcdB}$ & $4 \mathrm{dC}$ & $94 \mathrm{aA}$ & $80 \mathrm{abB}$ & $33 \mathrm{dC}$ \\
\hline CD 213 RR & $65 \mathrm{bcA}$ & $74 \mathrm{abA}$ & $4 \mathrm{~dB}$ & 83 abcA & $87 \mathrm{aA}$ & $39 \mathrm{cdB}$ \\
\hline CD 214 RR & $83 \mathrm{aA}$ & $79 \mathrm{aA}$ & $18 \mathrm{bcdB}$ & $92 \mathrm{abA}$ & 89 aA & $53 \mathrm{bB}$ \\
\hline BRS 242 RR & $77 \mathrm{abA}$ & $65 \mathrm{abcdB}$ & $34 \mathrm{aC}$ & $92 \mathrm{abA}$ & $82 \mathrm{abB}$ & $74 \mathrm{aB}$ \\
\hline BRS 243 RR & $69 \mathrm{abcA}$ & $70 \mathrm{abcA}$ & $27 \mathrm{abB}$ & $82 \mathrm{bcA}$ & $87 \mathrm{aA}$ & $69 \mathrm{aB}$ \\
\hline BRS 244 RR & $56 \mathrm{cA}$ & $63 \mathrm{bcdA}$ & $12 \mathrm{~dB}$ & $80 \mathrm{bA}$ & $86 \mathrm{aA}$ & $57 \mathrm{bB}$ \\
\hline BRS 246 RR & $77 \mathrm{abA}$ & $51 \mathrm{~dB}$ & $13 \mathrm{bcdC}$ & $90 \mathrm{abcA}$ & $75 \mathrm{bB}$ & $46 \mathrm{bcC}$ \\
\hline BRS 247 RR & $84 \mathrm{aA}$ & $59 \mathrm{cdB}$ & $26 \mathrm{abcC}$ & $92 \mathrm{abA}$ & $82 \mathrm{abB}$ & $46 \mathrm{bcC}$ \\
\hline BRS 255 RR & 72 abcA & $61 \mathrm{bcdB}$ & $16 \mathrm{bcdC}$ & $83 \mathrm{bcA}$ & 79 abA & $46 \mathrm{bcB}$ \\
\hline
\end{tabular}

*Médias seguidas de mesma letra, minúsculas na coluna e maiúsculas na linha, não diferem estatisticamente entre si pelo Teste de Tukey ao nível de 5\% de probabilidade.

Fonte: Elaboração dos autores.

No município de Guarapuava, apenas a cultivar BRS 243 RR apresentou índice de germinação inferior a $80 \%$. Entretanto, no município de Campo Mourão, este cultivar apresentou a maior porcentagem de germinação (94\%). Isso pode ser explicado levando-se em consideração os dados de precipitação e temperatura de ambos os locais de cultivo. A cultivar BRS 243 RR apresenta ciclo médio, com data de semeadura em 08/12/2006, em Guarapuava e seu desenvolvimento estendeu-se até o início do mês de maio/2007, época em que foi registrado maior período de precipitação pluvial (Figura 1). O mesmo não ocorreu em Campo Mourão (Figura 1), que apresentou precipitação de apenas 36,2 $\mathrm{mm}$ nos 15 dias que antecederam a colheita. Dados obtidos por Vieira et al. (1982), que avaliou 15 épocas de colheita, mostraram que precipitações de até $40 \mathrm{~mm}$ não provocam reduções acentuadas na germinação das sementes de soja.

A cultivar CD 212 RR, apesar de ter apresentado elevada germinação no município de Guarapuava (94\%), apresentou desempenho inferior no município de Guaíra (29\%), devido à pré-colheita ter coincidido com período de elevada precipitação $(156 \mathrm{~mm})$ associada à temperatura média mais elevada $\left(27^{\circ} \mathrm{C}\right)$ (Figura 1); por este motivo, em Guaíra, as cultivares de ciclo semiprecoce e médio apresentaram germinação abaixo do padrão nacional (80\%) (BRASIL, 2005). 
Figura 1. Dados de temperatura média e precipitação pluvial (colunas) observados nos municípios de Guarapuava PR, Campo Mourão - PR e Guaíra-SP, durante o ciclo da cultura da soja, iniciando na data de plantio referente a cada local, com dados agrupados de 5 em 5 dias.
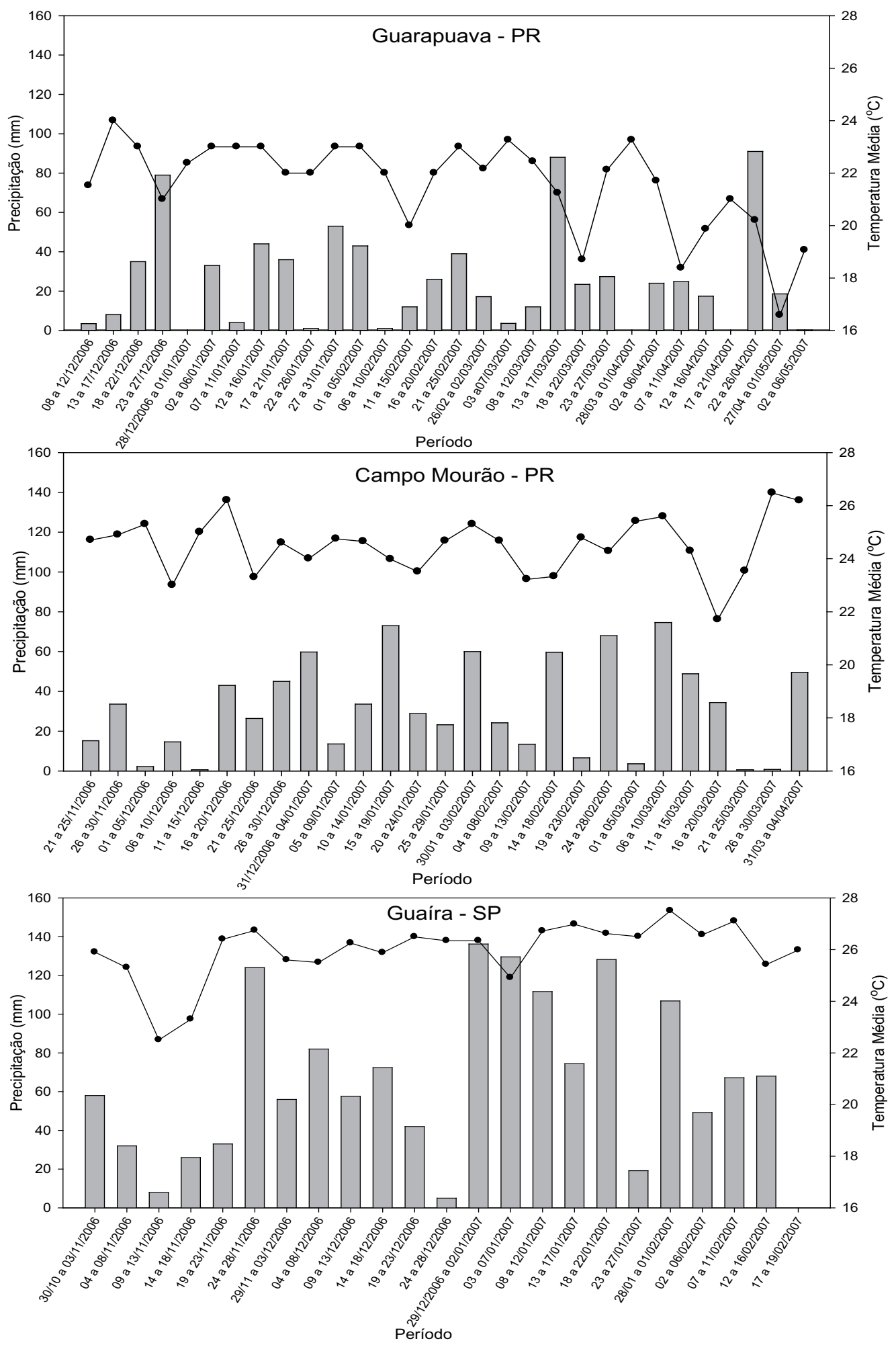

Fonte: IAPAR. 
Os testes de envelhecimento precoce e tetrazólio indicaram maior qualidade fisiológica das sementes produzidas no município de Guarapuava-PR. Este fatodeve-seascondiçõesambientaisdessemunicípio, as quais se assemelharam às recomendadas por França Neto, Henning e Krzyzanowski (1994), que sugeriram que a região para a produção de sementes de alta qualidade deve apresentar altitude superior a $700 \mathrm{~m}$, com predominância de condições de temperatura amena associada a baixos índices de precipitação no período de maturação a colheita. $\mathrm{Na}$ avaliação do envelhecimento precoce, no município de Guarapuava-PR, a cultivar BRS 242 $\mathrm{RR}$ demonstrou menor vigor (66\%), seguido pelas cultivares BRS 244 RR e BRS 255 RR. Em Campo Mourão, a cultivar BRS 243 RR se destacou, apresentando vigor de $85 \%$. O menor vigor $(58 \%$ e $1 \%$, respectivamente, para os locais de Campo Mourão e Guaíra) foi observado para a cultivar CD 212 RR.

Para o teste de Tetrazólio - vigor as cultivares que se destacaram em Guarapuava foram BRS 247 RR e CD 214 RR, com $84 \%$ e 83\%, respectivamente. A cultivar BRS 244 RR (56\%) apresentou o menor vigor. No município de Campo Mourão, a cultivar CD 214 RR (79\%) apresentou o maior vigor e BRS 246 RR (51\%) a menor média. Em Guaíra, todos as cultivares apresentaram resultados insatisfatórios, apresentando valores de vigor inadequados (abaixo de 49\%) conforme classificação estabelecida por França Neto, Krzyzanowski e Costa (1998).

Os resultados do Tetrazólio - viabilidade evidenciam que, no município de Guarapuava-PR, a cultivar CD 212 RR obteve maior média (94\%), não diferindo estatisticamente das cultivares BRS 247 RR, CD 214 RR, BRS 242 RR, BRS 246 RR e CD 213 RR (Tabela 4). A cultivar BRS 242 RR apresentou resultados superiores, entre os locais, com $83 \%$ de média geral na viabilidade do tetrazólio, dado este importante, pois, corrobora com os dados obtidos para o teste de germinação (Tabela 4). Os resultados do teste de germinação, envelhecimento precoce e de tetrazólio para Guarapuava concordaram com os resultados de Costa et al. (1994), os quais identificaram que a região onde se localiza esse município é a mais favorável para produção de sementes de soja de alta qualidade; estes autores também identificaram a região onde se localiza o município de Campo Mourão como medianamente favorável.

Nos três municípios avaliados, levando-se em consideração a média geral das cultivares, o principal dano que ocorreu em ordem de importância foi causado por umidade, seguido pelo mecânico e pelo ataque de percevejos (Tabela 5). Costa et al. (1995), avaliando o efeito da época de semeadura sobre a qualidade fisiológica de sementes de soja no estado do Mato Grosso, constataram elevados índices de deterioração por umidade devido às condições climáticas desfavoráveis. Constatações semelhantes foram encontradas por França Neto et al. (1993). Nas condições do estado do Paraná, Menon et al. (1993) concluíram que o alto grau de deterioração ocasionado por fatores climáticos adversos, esta relacionado a danos de umidade e mecânicos, os quais que contribuíram para a redução da qualidade das sementes de soja. Além disso, a deterioração por umidade pode resultar em maior índice de danos mecânicos na colheita, uma vez que sementes deterioradas são extremamente vulneráveis aos impactos mecânicos (FRANÇA NETO; KRZYZANOWSKI, 2000).

Além dos aspectos mencionados, os resultados indicaram que a deterioração por umidade, danos mecânicos e de lesões de percevejos, potencializam de forma irreversível os sérios problemas da baixa qualidade fisiológica das sementes. Áreas situadas ao norte do paralelo $24^{\circ} \mathrm{LS}$ (no município de Guaíra) apresentam menor potencial para a produção de sementes de qualidade (ARANTES et al., 1994). Isso ocorre devido o excesso hídrico e as elevadas temperaturas principalmente nas fases que antecedem a colheita, que favorecem o processo deterioração da semente (FRANÇA NETO et al., 2000). Além disso, Costa et al. (2005), avaliando a qualidade das sementes de soja produzidas no 
Brasil, observaram que o dano por percevejo foi mais relevante para a deterioração das sementes nas regiões de Minas Gerais, Mato Grosso do Sul e oeste e norte do Paraná.

No município de Guarapuava, a cultivar BRS 255 RR (71\%) foi a mais sensível ao dano por umidade na escala de 1-8 (danos leves), e o BRS 247 RR (40\%) o de menor dano. Entretanto, no dano por umidade na escala de 6-8 (danos severos), o cultivar BRS 243 RR apresentou 11\%, impossibilitando a utilização dessa semente, já que valores superiores a $10 \%$ são considerados inadequados para comercialização
(FRANÇA NETO; KRZYZANOWSKI; COSTA, 1998). Da mesma forma, o cultivar BRS 244 RR apresentou elevado índice de dano mecânico (12\%) na escala de 6-8 (Tabela 5). As cultivares CD 212 RR, CD 213 RR e BRS 255 RR não apresentaram problemas de dano mecânico, ficando com índices de $3 \%$ e $6 \%$ na escala de $6-8$, não apresentando restrições. As demais cultivares se mantiveram com índices entre $7 \%$ a 10\%, com qualidade fisiológica comprometida, sendo que o dano por percevejo nas escalas 1-8 e 6-8 não afetaram o vigor das sementes (Tabela 5).

Tabela 5. Valores médios de porcentagem do teste de tetrazólio referente a cada dano encontrado nos nove cultivares de soja com seu respectivo nível de agressividade (1-8) e (6-8), cultivados em Guarapuava-PR e Campo Mourão - PR e Guaíra-SP na safra 2006/2007.

\begin{tabular}{|c|c|c|c|c|c|c|}
\hline \multicolumn{7}{|c|}{ Guarapuava-PR } \\
\hline \multirow{2}{*}{ Cultivares } & \multicolumn{2}{|c|}{ Dano Mecânico } & \multicolumn{2}{|c|}{ Umidade } & \multicolumn{2}{|c|}{ Percevejo } \\
\hline & $(1-8)$ & $(6-8)$ & $(1-8)$ & $(6-8)$ & $(1-8)$ & $(6-8)$ \\
\hline CD 212 RR & 21 & 3 & 55 & 1 & 6 & 1 \\
\hline CD 213 RR & 21 & 6 & 56 & 6 & 4 & 0 \\
\hline CD 214 RR & 29 & 7 & 48 & 3 & 6 & 1 \\
\hline BRS 242 RR & 19 & 9 & 64 & 4 & 8 & 1 \\
\hline BRS 243 RR & 21 & 10 & 57 & 11 & 7 & 1 \\
\hline BRS 244 RR & 26 & 12 & 60 & 6 & 7 & 2 \\
\hline BRS 246 RR & 24 & 7 & 53 & 3 & 9 & 1 \\
\hline BRS 247 RR & 27 & 7 & 40 & 2 & 7 & 1 \\
\hline BRS 255 RR & 18 & 6 & 71 & 5 & 4 & 1 \\
\hline Média & 23 & 8 & 55 & 4 & 6 & 0.8 \\
\hline \multicolumn{7}{|c|}{ Campo Mourão-PR } \\
\hline \multirow{2}{*}{ Cultivares } & \multicolumn{2}{|c|}{ Dano Mecânico } & \multicolumn{2}{|c|}{ Umidade } & \multicolumn{2}{|c|}{ Percevejo } \\
\hline & $(1-8)$ & $(6-8)$ & $(1-8)$ & $(6-8)$ & $(1-8)$ & $(6-8)$ \\
\hline CD 212 RR & 11 & 7 & 56 & 9 & 18 & 2 \\
\hline CD 213 RR & 13 & 4 & 60 & 3 & 19 & 0 \\
\hline CD 214 RR & 21 & 6 & 50 & 4 & 21 & 2 \\
\hline BRS 242 RR & 20 & 7 & 57 & 5 & 20 & 5 \\
\hline BRS 243 RR & 27 & 8 & 45 & 2 & 15 & 2 \\
\hline BRS 244 RR & 13 & 6 & 63 & 5 & 18 & 2 \\
\hline BRS 246 RR & 22 & 13 & 56 & 8 & 19 & 5 \\
\hline BRS 247 RR & 17 & 7 & 47 & 7 & 25 & 4 \\
\hline BRS 255 RR & 24 & 10 & 55 & 8 & 17 & 3 \\
\hline Média & 19 & 7 & 54 & 5 & 19 & 3 \\
\hline
\end{tabular}


continuação

\begin{tabular}{lcccccc}
\hline \multicolumn{9}{c}{ Guaíra-SP } & \multicolumn{2}{c}{ Percevejo } \\
\hline \multirow{2}{*}{ Cultivares } & \multicolumn{2}{c}{ Dano Mecânico } & \multicolumn{2}{c}{ Umidade } & $(1-8)$ & $(6-8)$ \\
\hline CD 212 RR & $(1-8)$ & $(6-8)$ & $(1-8)$ & $(6-8)$ & 3 & 2 \\
CD 213 RR & 12 & 11 & 82 & 53 & 1 & 0 \\
CD 214 RR & 17 & 13 & 80 & 47 & 5 & 2 \\
BRS 242 RR & 7 & 4 & 79 & 34 & 10 & 3 \\
BRS 243 RR & 14 & 8 & 82 & 21 & 6 & 1 \\
BRS 244 RR & 8 & 8 & 80 & 21 & 3 & 1 \\
BRS 246 RR & 12 & 11 & 87 & 31 & 5 & 3 \\
BRS 247 RR & 12 & 10 & 84 & 42 & 5 & 2 \\
BRS 255 RR & 15 & 14 & 84 & 39 & 6 & 2 \\
Média & 12 & 10 & 80 & 39 & 35 & 1 \\
\hline
\end{tabular}

Fonte: Elaboração dos autores.

Em Campo Mourão, verificou-se que os danos mecânicos na escala de 6-8 (Tabela 5) das cultivares CD 212 RR, BRS 246 RR, BRS 247 RR e BRS 255 RR variaram de $7 \%$ a $10 \%$, o que explica os baixos índices de vigor observados (Tabela 4). Quanto aos danos causados por percevejo, verificou-se que nenhuma das cultivares apresentou valores superiores a $5 \%$ na escala de 6-8, indicando que a perda vigor não foi ocasionada por essa praga. Da mesma forma, em Guaíra, ocorreram danos mecânicos severos (escala 6-8) para todas as cultivares avaliadas, com exceção da cultivar BRS 242 RR (4\%). O dano por percevejo foram baixos (entre 0 e $3 \%$ ), demonstrando não ser a causa da perda de vigor neste local, resultados semelhante foram observados por Menon et al. (1993).

\section{Conclusões}

A qualidade fisiológica e o rendimento de sementes foram influenciados pelo ambiente de cultivo.

As sementes de soja provenientes da região de Guarapuava-PR apresentam maior germinação, vigor e viabilidade, embora apresentaram menor rendimento de sementes em comparação as regiões de Campo Mourão-PR e Guaíra-SP.
Os danos mecânicos e por umidade foram os principais responsáveis pela diminuição da germinação, vigor e viabilidade das sementes em todos os locais avaliados.

As cultivares CD 214 RR, BRS 246 RR e BRS 255 RR apresentaram elevado rendimento e qualidade fisiológica de sementes.

\section{Referências}

ABRATES - Vigor de sementes: conceitos e testes. In: KRZYZANOWSKI, F. C.; VIEIRA, R. D.; FRANÇA NETO, J. B. (Ed.). Associação Brasileira de Tecnologia de Sementes: Comitê de Vigor de Sementes. Londrina: Abrates, 1999. $218 \mathrm{p}$.

ARANTES, H. A. G.; ROCHA, V. S.; SILVA, E. A. M.; SEDIYAMA, T. Espessura do tegumento, embebição em água e qualidade fisiológica da semente de soja. Revista Ceres, Viçosa, v. 41, n. 234, p. 126-132, 1994.

ÁVILA, M. R.; BRACCINI, A. L. de; MOTTA, I. S. de; SCAPIM, C. A.; BRACCINI, M. C. L. Sowing seasons and quality of soybean seeds. Scientia Agricola, Piracicaba, v. 60, n. 2, p. 245-252, 2003.

BRACCINI, A. L.; REIS, M. S.; SEDIYAMA, C. S.; SCAPIM, C. A.; BRACCINI, M. C. L. Avaliação da qualidade fisiológica de sementes de soja, após o processo de hidratação-desidratação e envelhecimento acelerado. Pesquisa Agropecuária Brasileira, Brasília, v. 34, n. 6, p. 1053-1066, 1999. 
BRASIL. Ministério da Agricultura, Pecuária e Abastecimento. Regras para análise de sementes. Brasília: Mapa/ACS, 2009. 399 p.

. Normas especificas e os padrões de identidade e qualidade para produção e comercialização de sementes de algodão, arroz, aveia, azevém, feijão, girassol, mamona, milho, soja, sorgo, trevo, trigo, triticale e feijão caupi. Instrução Normativa $\mathrm{n}^{\mathrm{o}} 25$ de 16 de Dezembro de 2005. 2005. 45 p.

COSTA, N. P. da; MESQUITA, C. de M.; MAURINA, A. C.; NETO, J. B. F.; KRZYZANOWSKI, F. C.; OLIVEIRA, M. C. N.; HENNING, A. A. Perfil dos aspectos físicos, fisiológicos e químicos de sementes de soja produzidas em seis regiões do Brasil. Revista Brasileira de Sementes, Londrina, v. 27, n. 2, p. 1-6, 2005

COSTA, N. P. da; MESQUITA, C. de M.; MAURINA, A. C.; NETO, J. B. F.; KRZYZANOWSKI, F. C.; HENNING, A. A. Qualidade fisiológica, física e sanitária de sementes de soja produzidas no Brasil. Revista Brasileira de Sementes, Londrina, v. 25, n. 1, p. 128-132, 2003.

COSTA, N. P.; FRANÇA NETO, J. B. de; HENNING, A. A.; KRZYZANOWSKI, F. C.; CABRAL, N. T.; MENDES, E. M. C. Efeito da época de semeadura sobre a qualidade fisiológica de sementes de soja no Estado do Mato Grosso. Revista Brasileira de Sementes, Londrina, v. 17, n. 1, p. 107-112, 1995.

COSTA, N. P.; PEREIRA, L. A. G.; FRANÇA NETO, J. B. de; HENNING, A. A.; KRZYZANOWSKI, F. C. Zoneamento ecológico do Estado do Paraná para a produção de sementes de cultivares precoces de soja. Revista Brasileira de Sementes, Londrina, v. 16, n. 1, p. 12-19, 1994.

CRUZ, C. D. Programa genes: aplicativo computacional em genética e estatística. Viçosa: UFV, 2001. 648 p.

EMPRESA BRASILEIRA DE PESQUISA AGROPECUÁRIA - EMBRAPA. Tecnologias de produção de soja-região central do Brasil - 2007. Londrina: Embrapa Soja; Brasília: Embrapa Cerrados; Dourados: Embrapa Agropecuária Oeste, 2006. 225 p.

FRANÇA NETO, J. B.; KRZYZANOWSKI, F. C. Produção de sementes de soja: fatores de campo. Seed News, Pelotas, n. 4. p. 20-23, 2000.

Sementes enrugadas: novo problema na soja. Embrapa/Cnpso. 1990. 4 p. (Comunicado técnico, 49).

FRANÇA NETO, J. B.; KRZYZANOWSKI, F. C.; COSTA, N. P. O teste de tetrazólio em sementes de soja. Londrina: Embrapa-CNPSo, 1998. 72 p. (Documentos, 116).
FRANCA NETO, J. B.; HENNING, A. A.; KRZYZANOWSKI, F. C. Seed production and technology for the tropics. In: EMBRAPA. Centro Nacional de Pesquisa de Soja (Londrina, PR). Tropical soybean: improvement and production. Rome: FAO, p. 217-240. (FAO. Plant Production and Protection Series, 27). 1994.

FRANÇA-NETO, J. B.; KRZYZANOWSKI, F. C.; HENNING, A. A.; COSTA, N. P. Tecnologia de produção de sementes. In: EMBRAPA SOJA. A cultura da soja no Brasil. Londrina, 2000. 1 CD-ROM.

FRANÇA-NETO, J. B.; KRZYZANOWSKI, F. C.; HENNING, A. A.; WEST, S. H.; MIRANDA, L. C. Soybean seed quality as affected by shriveling due to heat and drought stresses during seed filling. Seed Science and Technology, v. 21, n. 1, p. 107-116, 1993.

HAMAWAKI, O. T.; JULIATTI, F. C.; GOMES, G. M.; RODRIGUES, F. A.; SANTOS, V. L. M. Avaliação da qualidade fisiológica e sanitária de sementes de genótipos de soja do ciclo precoce/médio em Uberlândia, Minas Gerais. Fitopatologia Brasileira. Brasília, v. 27, n. 2, p. 201-205, 2002.

KOLCHINSKI, E. M. Vigor de sementes de soja e aspectos do desempenho em campo. 2003. Tese (Doutorado em Fitotecnia) - Faculdade de Agronomia Eliseu Maciel da Universidade Federal de Pelotas, Pelotas.

KOLCHINSKI, E. M.; SCHUCH, L. O. B.; PESKE, S. T. Vigor de sementes e competição intra-específica em soja. Ciência Rural, Santa Maria, v. 35, n. 6, p. 12481256, 2005.

LIMA, W. F.; PÍPOLO, A. E.; MOREIRA, J. U. V.; CARVAlHO, C. G. P.; PRETE, C. E. C.; ARIAS, C. A. A.; OLIVEIRA, M. F.; SOUZA, G. E.; TOLEDO, J. F. F. Interação genótipo-ambiente de soja convencional e transgênica resistente a glifosato, no Estado do Paraná. Pesquisa Agropecuária Brasileira, Brasília, v. 43, n. 6, p. 729-736, 2008.

MARQUES, M. C.; HAMAWAK, O. T.; SEDIYAMA, T.; BUENO, M. R.; REIS, M. S.; CRUZ, C. D.; NOGUEIRA, A. P. O. Adaptabilidade e estabilidade de genótipos de soja em diferentes épocas de semeadura. Bioscience Journal, Uberlandia, v. 27, n. 1, p. 59-69, 2011.

MENON, J. C. M.; BARROS, A. C. S. A.; MELlO, V. D. C.; ZONTA, E. P. Avaliação da qualidade física e fisiológica da semente de soja produzida no estado do Paraná, na safra 1989/1990. Revista Brasileira de Sementes, Londrina, v. 15, n. 2, p. 203-208, 1993. 
MEOTTI, G. V.; BENIN, B.; SILVA, R. R.; BECHE, E.; MUNARO, L. B. Épocas de semeadura e desempenho agronômico de cultivares de soja. Pesquisa Agropecuária Brasileira, Brasília, v. 47, n. 1, p. 14-21, 2012.

SCHEEREN, B. R.; PESKE, S. T.; SCHUCH, L. O. B.; BARROS, A. C. A. Qualidade fisiológica e produtividade de sementes de soja. Revista Brasileira de Sementes, Londrina, v. 32, n. 3 p. 35-41, 2010.

SILVA, J. B. da; LAZARINI, E.; SÁ, M. E. de. Comportamento de sementes de cultivares de soja, submetidos a diferentes períodos de envelhecimento acelerado. Bioscience Journal, Uberlândia, v. 26, n. 5, p. 755-762, 2010.
VASCONCELOS, E. S. de; REIS, M. S.; SEDYIAMA, T.; CRUZ, C. D. Qualidade fisiológica de sementes de cultivares e linhagens de soja no Estado de Minas Gerais. Acta Scientiarum Agronomy, Maringá, v. 31, n. 2, p. 307312, 2009.

VIEIRA, L. R. D.; SEDIYAMA, J.; SILVA, R. E.; SEDIYAMA, C. S.; THIEBAUT, J. T. I.; XIMENES, P. A. Estudo da qualidade fisiológica de semente de soja (Glicine max (L.) Merrill) cultivar UFV-1 em quinze épocas de colheita. In: SEMINÁRIO NACIONAL DE PESQUISA DE SOJA, 2., 1982, Brasília. Anais... Londrina: EMBRAPA/CNPSo, 1982. v. 1, p. 633-644. 